\title{
Sonographic Demonstration of a Gastrocnemius Fascial Defect: A Rare Cause of Calf Pain
}

\author{
R Bullock ${ }^{1}$, DP Soares ${ }^{1}$, D Sawh ${ }^{2}$
}

\begin{abstract}
Fascial defects with muscular herniation are an uncommon, treatable cause of calf pain. Differential diagnosis includes deep vein thrombosis, compartment syndrome, soleus strain/tear, and muscle or subcutaneous tumour. In this case, sonography was more sensitive for diagnosis than magnetic resonance imaging.
\end{abstract}

Keywords: calf muscle herniation, dynamic sonography, gastrocnemius fascial defect, muscle herniation

\section{Demostración sonográfica de un defecto fascial del gastrocnemio: una causa rara del dolor de pantorrilla \\ R Bullock ${ }^{1}$, DP Soares ${ }^{1}$, D Sawh ${ }^{2}$}

\begin{abstract}
RESUMEN
Los defectos fasciales con herniación muscular son una causa poco frecuente y tratable del dolor de pantorrilla. El diagnóstico diferencial incluye trombosis venosa profunda, síndrome compartimental, distensión o desgarro del sóleo, y tumor subcutáneo o muscular. En este caso, la sonografía resultó más sensible para el diagnóstico que la tomografía por resonancia magnética.
\end{abstract}

Palabras clave: Herniación del músculo de la pantorrilla, sonografía dinámica, defecto fascial del gastrocnemio, herniación muscular

West Indian Med J 2018; 67 (2): 153

\section{INTRODUCTION}

Fascial defects resulting in muscular herniation are an uncommon cause of calf pain. The differential diagnosis for this condition includes deep vein thrombosis, compartment syndrome, soleus strain/tear, and muscle or subcutaneous tumour. As a treatable cause of calf pain, it is important to identify this condition correctly. Sonography is a readily available, inexpensive, noninvasive image modality and can be more sensitive in the diagnosis of the condition compared to routine magnetic resonance imaging (MRI), as is demonstrated by this case.
From: ${ }^{1}$ Section of Radiology, Department of Surgery, Radiology, Anaesthesia and Intensive Care, University Hospital of the West Indies and The University of the West Indies, Mona, Kingston, Jamaica, West Indies and ${ }^{2}$ Orthopaedic Department, Bustamante Hospital for Children, Kingston, Jamaica, West Indies.
Correspondence: Dr DP Soares, Section of Radiology, Department of Surgery, Radiology, Anaesthesia and Intensive Care, University Hospital of the West Indies, Kingston 7, Jamaica, West Indies. Email: deanne.soares@uwimona.edu.jm 


\section{CASE REPORT}

A 12-year-old girl presented to the Orthopaedic Department of the Bustamante Hospital for Children, Jamaica, with a four-year history of recurrent calf pain following muscular exertion. This was exacerbated by the fact that she was active in sports at school. Her remaining medical history was non-contributory. On clinical examination, an area of tenderness was located in the distal portion of the postero-lateral aspect of the leg overlying the lateral head of the gastrocnemius (just proximal to the tendinous continuation with the soleus muscle). A defect within the fascia was perceived at this location. Magnetic resonance imaging was performed in an attempt to confirm the presence of a fascial defect, but was found to be negative (Fig. 1). Dynamic imaging with sonography was subsequently done following exercise (walking for approximately 10 minutes in the X-ray department), insonating at $7.5 \mathrm{MHz}$, overlying the area of localized tenderness. At this point, a $2 \mathrm{~mm}$ focal area of fascial elevation with herniation of the superficial fibres of the lateral head of the gastrocnemius was demonstrable (Fig. 1). Based on the sonographic findings, surgery was offered. At surgery, a $1.0 \times 1.5 \mathrm{~cm}$ fascial defect was confirmed overlying the lateral head of the gastrocnemius (Fig. 2). The defect was repaired using a mesh graft.

The patient remained well on review three years following surgery and was able to exercise fully and engage in competitive sports.

\section{DISCUSSION}

Herniated muscle in the extremities is an uncommon but important clinical entity to recognize. Ihde is often cited as being the first to describe this entity in 1929 (1), but in an article by Nguyen et al, it is stated that Ihde gave credit to Richet for first describing the entity in 1853 (2). Normal muscle is covered by a thin connective tissue fascia which prevents the muscle from herniating. When a defect is present in the fascia, muscle may herniate especially when the muscle is contracted. These defects may be found at anatomical sites of weakness (such as points where vessels traverse the fascia) or they may be secondary to acquired defects following trauma $(3,4)$. They may cause intermittent swelling, or pain, particularly on exertion (5). They involve more commonly the tibialis anterior than the gastrocnemius, as is reflected in the literature, only a few of which are cited here (2, 6-8). Anatomical vulnerability is cited as the cause of this, with herniation of the muscle usually occurring through defects in the deep fascia, with or without the presence of perforating cutaneous vessels (9). Muscle hernias have been described in both the adult and paediatric populations. In a series of 16 paediatric patients, Jarrett et al found a female predominance and a mean age of 13.8 years, similar to our patient's profile (10). In adult populations, these findings have been most often described in athletic males including soldiers $(8,11,12)$.

Both MRI (13) and ultrasound (14) have been used to establish the diagnosis of a muscle hernia, with demonstration being facilitated by activity within the muscle $i e$ dynamic imaging. Both exercising the leg and bedside manoeuvres (such as plantar flexion, squatting or standing) prove useful (10). Dorsiflexion has also proven to be useful (8). Though often thought of as a superior modality to ultrasound, MRI is difficult to perform dynamically due to image artefacts created by patient motion. Ultrasound readily allows for such dynamic assessment. Due to the superficial location of these muscle hernias, the use of a higher frequency probe is not just possible but necessary, with the result being of greater image resolution, advantageous to the detection of this clinical entity. Three-dimensional sonographic imaging has also been suggested as increasing the conspicuity of small hernias (15). Dynamic ultrasound has been shown to be more accurate than MRI at identifying muscle hernias with accuracies of $83 \%$ versus $17 \%$, respectively (16).

The sonographic features of muscle hernias are characteristic and exclude alternative clinical diagnoses such as tumours and muscle tears. Doppler ultrasound facilitates confirmation or exclusion of deep venous thrombosis (DVT), a potentially lethal cause of calf pain. Advantages of sonography include the ability to examine the patient dynamically, the lack of ionizing radiation, and its affordability and ready availability. Clinical examination helps to establish the site of pain or swelling. Exercising the muscle makes the fascial defect more apparent by accentuating the degree of muscle herniation $(6,17)$. A skin marker at the site of defect or swelling, to facilitate more focussed sonographic examination, is useful.

A high-frequency transducer, usually a minimum of 7.5 MHz, should be used (the choice of transducer also being guided by the size of the patient and the depth of defect), and the gain and focus should be set to optimize the near field. Graded compression should be applied to avoid effacing the hernia. It may be necessary to get the patient to contract the muscle or to stand during the examination. Normal muscle is covered by thin echogenic fascia. At sonography, if muscle herniates through 
a fascial defect, the muscle will appear as a mass with a convex outer border. The muscle septa may produce a spoke-like appearance of echogenic lines radiating from the centre of the fascial defect. More subtle features include focal thinning or mild elevation of the fascia (18). Prominent arterial pulsation can be identified in some cases using Doppler sonography, lending support to the theory that muscle herniation occurs at sites of weakness in which vessels penetrate the fascia (19).

This case highlights aspects regarding choice of imaging as well as the sonographic features of this muscle hernia. It is noteworthy that an MRI performed prior to the patient's ultrasound revealed no abnormality,

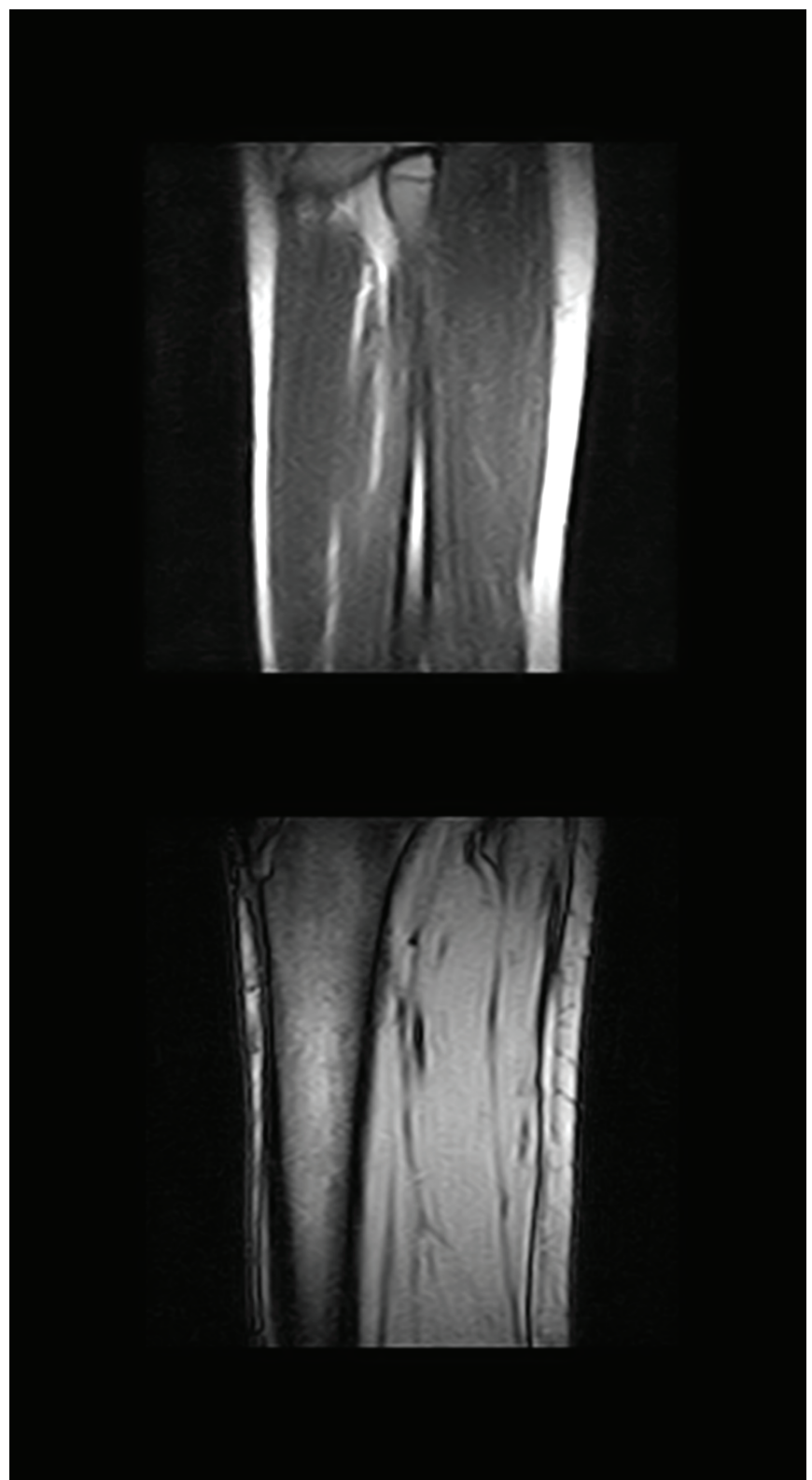

Fig. 1: Sagittal T1 weighted image (T1WI) and short tau inversion recovery (STIR) image overlying the gastrocnemius. even retrospectively (Fig. 1). At ultrasound, we were able to demonstrate, following a 10-minute walk, a fascial defect at the site of the patient's pain. At this site, we demonstrated a $2 \mathrm{~mm}$ focal area of fascial elevation through which superficial fibres of the lateral gastrocnemius muscle were seen to herniate (Fig. 2).

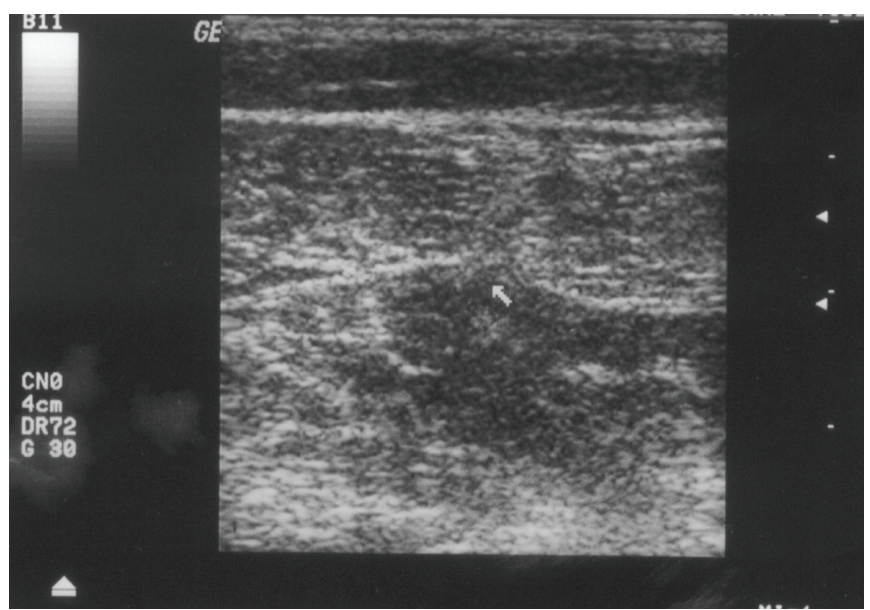

Fig. 2: Longitudinal sonogram overlying the fascial defect. The arrow shows the starburst appearance of the hernia.

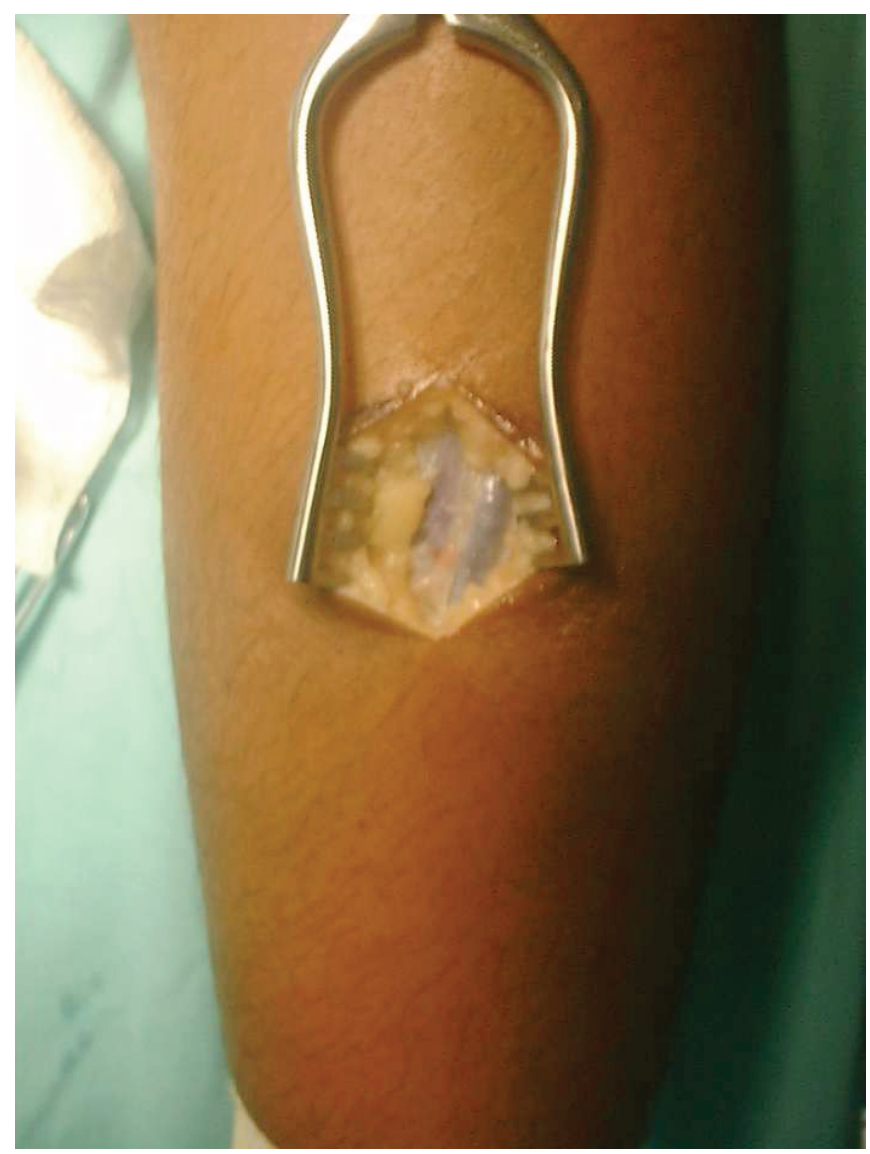

Fig. 3: Surgical demonstration of the defect. To the right of the defect, a blood vessel is evident. 
Most muscle hernias are treated by reassurance because they produce few symptoms and do not affect function. Compression bandages can also be used to relieve symptoms $(8,20)$. Painful hernias may limit sporting activities, and surgery has been found to provide an acceptable outcome $(7,10)$. Complications of surgery include compartment syndrome, infection and hernia recurrence (21-23). Patients are often concerned that the palpable lump is a tumour. The hernia can be shown to the patient using sonography as was done in this case. Surgery was confirmative and successful and showed a crossing vessel at the site of fascial weakness (Fig. 3). Alternative diagnoses such as muscle tears and tumours were excluded. Most importantly, our young patient was able to resume her athletic pursuits.

\section{REFERENCES}

1. Ihde H. On muscular hernias of the leg. Acta Chirurgica Scandinavica 1929; 65: 97-120

2. Nguyen JT, Nguyen JL, Wheatley MJ, Nguyen TA. Muscle hernias of the leg: a case report and comprehensive review of the literature. Can J Plast Surg 2013; 21: 243-7.

3. Bergmann G, Ciritsis BD, Wanner GA, Simmen HP, Werner CM, Osterhoff G. Gastrocnemius muscle herniation as a rare differential diagnosis of ankle sprain: case report and review of the literature. Patient Saf Surg 2012; 6: 5 .

4. Hegde AS. An interesting case of post traumatic tibialis anterior muscle herniation. Kathmandu Univ Med J 2013; 11: 332-4.

5. Alfageme F, Morales V, Garcia C, Miguelez AP, Dominguez E, Segurado A. Transfacial muscular hernia: an unusual cause for a "hide and seek" subcutaneous nodule. Dermatology Online Journal 2011; 17: 4.

6. Bates DG. Dynamic ultrasound findings of bilateral anterior tibialis muscle herniation in a pediatric patient. Pediatr Radiol 2001; 31: 753-5.

7. Miniaci A, Rorabeck CH. Tibialis anterior muscle hernia: a rationale for treatment. Can J Surg 1987; 30: 79-80.
8. Rho NK, Kim WS, Kim YJ, Yoo KH, Kim BJ, Kim MN. The use of dynamic ultrasonography for the confirmation of lower leg muscle herniation. Annals of Dermatology (Seoul) 2008; 20: 190-2.

9. Verbov J. Muscle herniation of the lower legs. Br J Dermatol 1976; 95: 329-30.

10. Jarrett DY, Kramer DE, Callahan MJ, Kleinman PK. US diagnosis of pediatric muscle hernias of the lower extremities. Pediatr Radiol 2013; 43 Suppl 1: S2-7.

11. Azar FM, Pickering RM. Sports medicine: traumatic disorders. In: Canale ST, Beaty JH, eds. Campbell's operative orthopedics. Volume 3, $12^{\text {th }}$ edition. Philadelphia, PA: Mosby/Elsevier; 2012: 2311-64.

12. Berglund HT, Stocks GW. Muscle hernia in a recreational athlete. Orthop Rev 1993; 22: 1246-8.

13. Mellado JM, Perez del Palomar L. Muscle hernias of the lower leg: MRI findings. Skeletal Radiol 1999; 28: 465-9.

14. Bianchi S, Abdelwahab IF, Mazzola CS, Ricci G, Damiani S. Sonographic examination of muscle herniation. J Ultrasound Med 1995; 14: $357-60$.

15. Gokhale S. Three-dimensional sonography of muscle hernias. J Ultrasound Med 2007; 26: 239-42.

16. Kramer DE, Pace JL, Jarrett DY, Zurakowski D, Kocher MS, Michell LJ. Diagnosis and management of symptomatic muscle herniation of the extremities: a retrospective review. Am J Sports Med 2013; 41: 2174-80.

17. Artul S, Habib G. The importance of dynamic ultrasound in the diagnosis of tibialis anterior muscle herniation. Crit Ultrasound J 2014; 6: 14.

18. Beggs I. Sonography of muscle hernias. AJR Am J Roentgenol 2003; 180: $395-9$.

19. Braunstein JT, Crues JV $3^{\text {rd }}$. Magnetic resonance imaging of hereditary hernias of the peroneus longus muscle. Skeletal Radiol 1995; 24: 601-4.

20. Lane JE, Woody CM, Lesher JL. Tibialis anterior muscle herniation. Dermatol Surg 2002; 28: 641-2.

21. Miniaci A, Rorabeck CH. Compartment syndrome as a complication of repair of a hernia of the tibialis anterior. A case report. J Bone Joint Surg Am 1986; 68: 1444-5.

22. Wolfort GF, Mogelvang C, Filtzer HS. Anterior tibial compartment syndrome following muscle hernia repair. Arch Surg 1973; 106: 97-9.

23. Siliprandi L, Martini G, Chiarelli A, Mazzoleni F. Surgical repair of an anterior tibialis muscle hernia with Mersilene mesh. Plast Reconstr Surg 1993; 91: 154-7. 